\title{
The Outcome of Sorafenib Therapy on Unresectable Hepatocellular Carcinoma: Experience of Conversion and Salvage Hepatectomy
}

\author{
TOSHIAKI YOSHIMOTO ${ }^{1}$, SATORU IMURA ${ }^{1}$, YUJI MORINE ${ }^{1}$, TETSUYA IKEMOTO ${ }^{1}$, \\ YUSUKE ARAKAWA $^{1}$, SHUICHI IWAHASHI ${ }^{1}$, YU SAITO ${ }^{1}$, CHIE TAKASU $^{1}$, \\ DAICHI ISHIKAWA ${ }^{1}$, HIROKI TERAOKU ${ }^{1}$, YOSHIMI BANDO ${ }^{2}$ and MITSUO SHIMADA ${ }^{1}$ \\ ${ }^{I}$ Department of Surgery, Tokushima University, Tokushima, Japan; \\ ${ }^{2}$ Division of Pathology, Tokushima University Hospital, Tokushima, Japan
}

\begin{abstract}
Background/Aim: We report the outcomes of sorafenib therapy for advanced hepatocellular carcinoma (HCC) in our Department. Patients and Methods: Thirty-eight patients with unresectable HCC who were administrated sorafenib from 2009 to 2015 were investigated retrospectively. Results: The 1-year overall survival rate was 59.3\%. The macroscopic vascular invasion and response rate were independent prognostic factors of survival. Surgical resection after sorafenib achieved long-term survival in two cases. Case 1: A patient with locally unresectable HCC showed significant response induced by sorafenib, which allowed complete surgical resection. This tumor tested positive for FGF4. Case 2: A patient with a history of hepatectomy for HCC had multiple distant metastases. Most lesions were reduced in size after sorafenib therapy and new lesions in the remnant liver and residual lung metastases were resected. The sorafenibresistant lesions were negative for FGF4. Conclusion: Sorafenib combined with surgical resection is a feasible option in advanced HCC patients, if sorafenib has been effective.
\end{abstract}

Hepatocellular carcinoma (HCC) remains a major health problem throughout the world, and it accounts for more than 600,000 new cases per year. The well-known risk factors of HCC are chronic infection with hepatitis B virus or hepatitis C virus, non-alcoholic fatty liver disease, alcohol abuse, cigarette smoking and intake of aflatoxins. Complete surgical resection or liver transplantation for $\mathrm{HCC}$ is the only chance for a cure;

Correspondence to: Prof. Satoru Imura, Department of Surgery, Tokushima University, 3-18-15 Kuramoto-cho, Tokushima 7708503, Japan. Tel: +81 886337139, Fax: +81 886319698, e-mail: imura.satoru@tokushima-u.ac.jp

Key Words: Hepatic resection, hepatocellular carcinoma, sorafenib, unresectable, conversion. therefore, down-staging therapy for advanced HCC is essential for long-term survival. However, no useful systemic therapy existed before the introduction of sorafenib.

Sorafenib is a multikinase inhibitor that targets Raf kinase, vascular endothelial growth factor receptors 1,2, and 3, and platelet-derived growth factor receptor $\beta$. Sorafenib has been the standard treatment for first-line therapy $(1,2)$ for advanced or metastatic HCC in patients with Child-Pugh A liver function. Recently, several authors have reported that sorafenib is a viable therapy that can achieve significant pathological tumor regression and allow complete surgical resection $(3,4)$. However, the response rate to sorafenib therapy is low (between $2 \%$ and $3.3 \%$ ) $(1,2)$. In 2012, Arao et al. reported that fibroblast growth factor (FGF) 3/4 amplification was a potentially useful biomarker for sorafenib responsiveness by comparative genomic hybridization (5).

We present the outcomes of sorafenib treatment in our department and report the cases of a patient who showed significant histopathologic response induced by sorafenib treatment, which allowed complete surgical resection in a patient with locally unresectable HCC and a patient who underwent salvage hepatectomy after sorafenib treatment. In addition, the resected tumor of the first patient and the primary tumor of the second patient were positive for FGF4 using immunohistochemistry.

\section{Patients and Methods}

This study was performed in accordance with the Helsinki Declaration of the World Medical Association. This retrospective study enrolled 38 patients with advanced HCC treated at Tokushima University Hospital from 2009 to 2015. Of these, 18 patients who underwent initial surgical resection with curative intent and 5 patients who underwent another previous therapy were included in this study.

The 38 patients included 28 men and 10 women, of mean \pm SE age $63.6 \pm 1.9$ years (range $=33-84$ years). The median patient follow-up for all patients was 13.3 month (range=2.0-98.5 months). Staging was 
Table I. Association between clinicopathological features and 1-year OS rates in patients with advanced HCC treated with sorafenib.

\begin{tabular}{lccc}
\hline Factors & & $\begin{array}{c}1 \text {-year OS } \\
(\%)\end{array}$ & $p$-Value \\
& & $59.3 / 68.9$ & 0.37 \\
\hline Age & $<65 />65$ & $63.2 / 50.0$ & 0.80 \\
Gender & $\mathrm{M} / \mathrm{F}$ & $63.6 / 61.9$ & 0.76 \\
DCP & $<100 \mathrm{mAU} / \mathrm{ml}$ & \\
& $>100 \mathrm{mAU} / \mathrm{ml}$ & & \\
$\Delta \mathrm{DCP}(\%)$ & $<0 \% / \geq 0 \%$ & $75.0 / 57.2$ & 0.35 \\
AFP & $<100 \mathrm{ng} / \mathrm{ml} / \geq 100 \mathrm{ng} / \mathrm{ml}$ & $79.8 / 44.6$ & $<0.03$ \\
$\Delta \mathrm{AFP}(\%)$ & $<42 \% / \geq 42 \%$ & $74.5 / 48.8$ & $<0.03$ \\
Alb & $<3.5 \mathrm{~g} / \mathrm{dl} / \geq 3.5 \mathrm{~g} / \mathrm{dl}$ & $61.5 / 58.1$ & 0.57 \\
Hepatitis & $-/ \mathrm{B} / \mathrm{C}$ & $51.9 / 62.5 / 60.6$ & 0.50 \\
History of Hx & $-/+$ & $52.9 / 66.2$ & 0.10 \\
MVI & $-/+$ & $72.1 / 31.3$ & $<0.01$ \\
Response rate & $\mathrm{PR}, \mathrm{SD} / \mathrm{PD}$ & $93.3 / 37.7$ & $<0.01$ \\
Adverse effects & $-/+$ & $48.5 / 70.0$ & 0.42 \\
Hand-foot syndrome & $-/+$ & $59.1 / 62.5$ & 0.66 \\
Hx after sorafenib & $-/+$ & $56.9 / 100$ & $<0.05$ \\
\hline
\end{tabular}

DCP: Des- $\gamma$-carboxy prothrombin; AFP: alpha-fetoprotein; Hx: hepatic resection; MVI: macroscopic vascular invasion; PR: partial response; SD: stable disease; PD: progressive disease.

defined according to the criteria of the Liver Cancer Study Group of Japan. Fourteen patients diagnosed with stage IVa and the population of each stage IVb, III and II were 11, 12 and 1, respectively. Any adverse effects occurred in 20 patients $(50 \%)$ and hand-foot syndrome accounted for $64 \%$ of adverse effects. In all 38 patients, the mortality due to the side effects of sorafenib was $0 \%$. In the follow-up observations, the Response Evaluation Criteria in Solid Tumors (RECIST) criteria were used as a radiological assessment tool for determining the response rate. Serum des- $\gamma$-carboxy prothrombin (DCP) and alpha-fetoprotein (AFP) levels were measured before sorafenib administration as a base line. The DCP and AFP variation rate $(\triangle \mathrm{DCP}(\%)$ and $\triangle \mathrm{AFP}(\%))$ were defined as the percentage of change between the baseline and the 3 months after administration (6).

Informed consent statement. All procedures were in accordance with the ethical standards of the responsible committee on human experimentation (institutional and national) and with the Helsinki Declaration of 1964 and later revision. Informed consent or substitute for it was obtained from all patients for being included in the study.

Statistical analysis. Univariate analysis of differences between groups was determined by log-rank tests and multivariate analysis by chi-squared tests. Survival curves were plotted using the KaplanMeier method and 1-year OS rate was analyzed. Two-sided $p$-values $<0.05$ were considered statistically significant. All statistical analyses were performed using JMP version 13 statistical software (SAS, Campus Drive Cary, NC, USA).

\section{Results}

Overall survival. Survival curves of the 38 patients were plotted by the Kaplan-Meier method. The 1-year OS rate was $59.3 \%$ and median overall survival was 13.3 months (SD 2.48) (Figure 1).
Table II. Multivariate analysis of factors associated with 1-year OS rates in patients with advanced HCC treated with sorafenib.

\begin{tabular}{lccc}
\hline Factors & & Odds ratio $(95 \% \mathrm{CI})$ & $p$-Value \\
\hline AFP & $\geq 100 \mathrm{ng} / \mathrm{ml}$ & $2.632(0.433-18.715)$ & 0.29 \\
$\Delta$ AFP $(\%)$ & $\geq 42 \%$ & $1.458(0.213-10.024)$ & 0.69 \\
MVI & + & $6.930(1.135-66.023)$ & $<0.05$ \\
Response rate & PD & $8.745(1.447-84.898)$ & $<0.03$ \\
\hline
\end{tabular}

AFP: Alpha-fetoprotein; MVI: macroscopic vascular invasion; PD: progressive disease.

Univariate and multivariate analysis of clinicopathological features associated with overall survival. Table I shows univariate analyses of clinicopathological features associated with OS. The macroscopic vascular invasion (MVI) $(p<0.01)$, AFP $\geq 100 \mathrm{ng} / \mathrm{ml}(p<0.03), \Delta$ AFP $(\%) \geq 42 \%$ $(p<0.03)$, response rate (progressive disease (PD)) $(p<0.01)$ and surgical intervention after sorafenib administration $(p<0.05)$ were significantly prognostic of 1 -year OS. Table II shows multivariate analyses of clinicopathological features associated with OS. MVI $(p<0.05)$ and response rate (PD) $(p<0.03)$ were independently prognostic of survival in this patient cohort. Surgical intervention after sorafenib administration was exclude from multivariate analyses because of the smallness of population; the following two cases.

\section{Case 1}

Conversion hepatectomy. A 50-year-old male with a history of hepatitis type B was referred to our hospital because of a liver tumor. He had never had anti-hepatitis B treatment including interferon or nucleoside analogues. Serum DCP was $23,635 \mathrm{mAU} / \mathrm{ml}$ and AFP was $2,308 \mathrm{ng} / \mathrm{ml}$. A computed tomography (CT) scan and magnetic resonance imaging (MRI) showed a large HCC, $12 \mathrm{~cm}$ in diameter, on the right anterior segment of the liver. In addition, multiple intrahepatic metastases were detected in posterior and medial segment (Figure 2A and B). For a curative resection, an extended right lobectomy was needed; however, the estimated remnant liver volume using simulation software was less than $30 \%$.

Sorafenib was administered orally at a dose of $800 \mathrm{mg}$ twice daily. One month later, elevation of transaminase occurred that required discontinuation of treatment. Both DCP and AFP were dramatically decreased to $577 \mathrm{mAU} / \mathrm{ml}$ and $17 \mathrm{ng} / \mathrm{ml}$, respectively. After resolution of elevated transaminase, sorafenib was reintroduced at a dose of $400 \mathrm{mg}$ orally. Two months after starting sorafenib treatment, serum AFP and DCP levels were within normal range. After 3 months of sorafenib treatment, a CT scan showed that the tumor size had been reduced dramatically and that it had a 


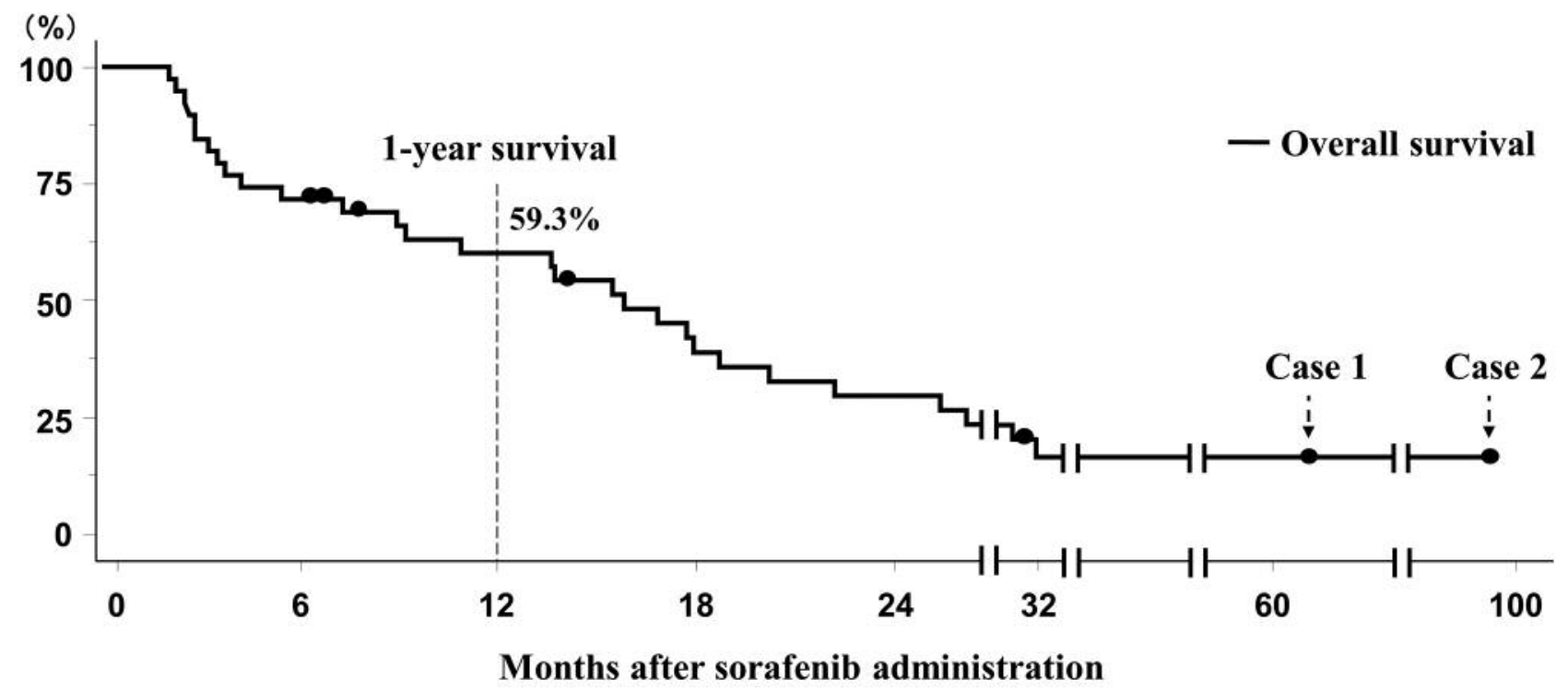

Figure 1. Overall survival curve of 38 patients with advanced HCC treated with sorafenib.

large necrosis area. No intrahepatic metastasis lesions were detected on a CT scan or MRI (Figure 2C). A right lobectomy was performed for curative surgical resection.

Macroscopically, the resected specimens showed extensive necrosis in most parts of the tumor. Histopathologically, the main tumor showed a pathologic complete response without any viable cells (Figure 2D). A small stellate nodule with viable tumor cells, $2 \mathrm{~cm}$ in diameter, was found (Figure 2E). In this nodule, tumor cells were positive for FGF4 (Figure $2 \mathrm{~F}$ ). The patient remained well, without any evidence of recurrence 4.5 years after surgery.

\section{Case 2}

Salvage hepatectomy. A 60-year-old male with a history of hepatitis type B had HCC in the right liver lobe, and underwent right lobectomy in 2007. Pathologically, the tumor was moderately to poorly differentiated HCC with microscopic portal vein invasion and intrahepatic metastasis, and it was positive for FGF4. Eighteen months after hepatectomy, multiple lung metastasis and hilar lymph node (LN) metastasis occurred (Figure 3A) and the patient received general chemotherapy. A regimen of gemcitabine plus low-dose 5-FU/CDDP and Tegafur/gimeracil/oteracil (TS-1) combined with interferon alpha were administered, but it was not effective, and sorafenib was started at a dose of $800 \mathrm{mg}, 29$ months after hepatectomy. At this point, serum DCP was $130 \mathrm{mAU} / \mathrm{ml}$ and AFP was $8 \mathrm{ng} / \mathrm{ml}$. Three months later, serum DCP decreased to $40 \mathrm{mAU} / \mathrm{ml}$ and a CT scan showed a reduction in the lung and LN metastases (Figure 3B). Serum AFP level didn't change.
The sorafenib dose was reduced to $400 \mathrm{mg} /$ day because the patient reported having diarrhea, but sorafenib was administered continuously. Under careful observation, 25 months after starting sorafenib treatment, a CT scan showed a recurrent tumor in the medial segment (Figure 3C) that was increasing in size. Other metastatic lesions were controlled, and medial segmentectomy was performed (Figure 3D). Pathologically, the recurrent tumor showed moderately to poorly differentiated HCC that was negative for FGF4 (Figure 3E).

Sorafenib was then re-introduced and continued, but one lung tumor remained and it was gradually increasing in size (Figure 3F). The residual lung tumor was resected 40 months after hepatectomy (Figure 3G), and the patient was diagnosed with HCC metastasis that was negative for FGF4 (Figure $3 \mathrm{H})$. The patient's postoperative course was uneventful and he remained alive 8 years after sorafenib induction.

\section{Discussion}

Since sorafenib was approved in Japan, it has been administered to many patients with advanced HCC, and it was expected to improve survival and the time to progression in these patients $(1,2)$. However, among the advanced HCC patients treated with sorafenib, a few achieved complete response (CR) and there are no definitive biomarkers for predicting effect of sorafenib. A recent study reported that early AFP response to sorafenib may be useful for predicting survival in patients with advanced HCC (7). In our study, serum AFP level at baseline and the percentage of change 
A

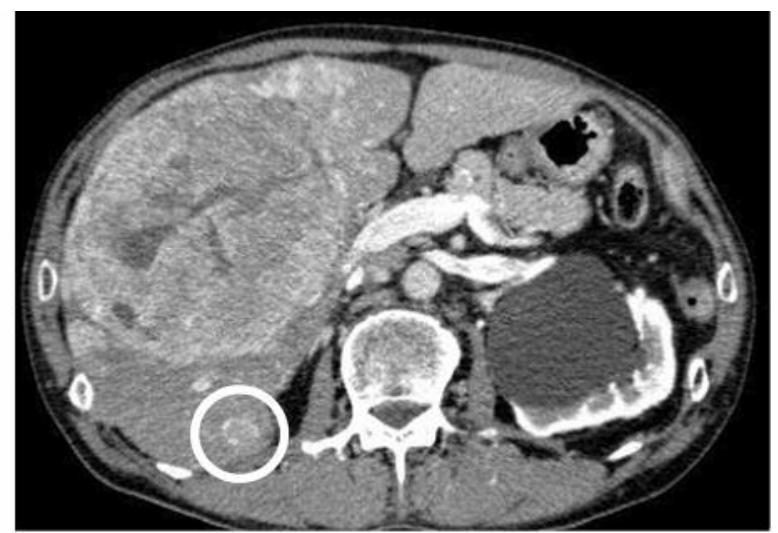

C

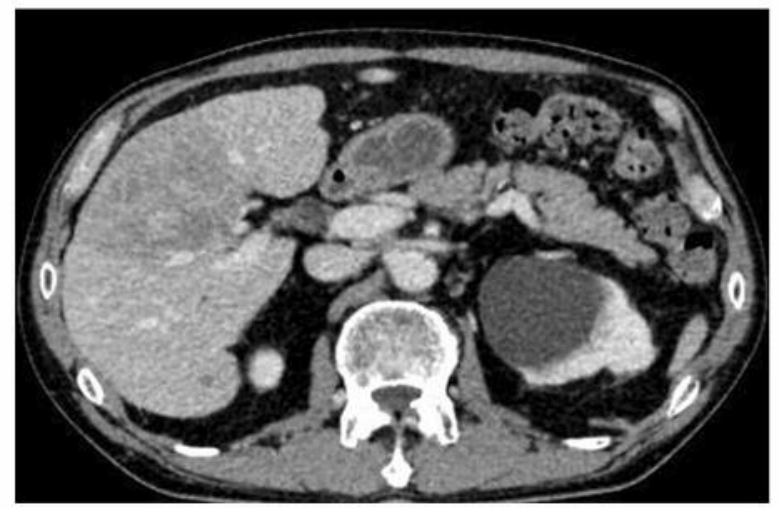

E

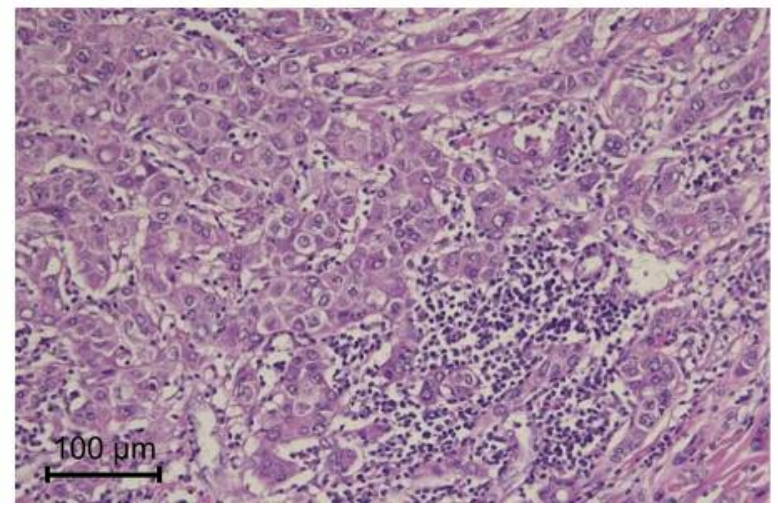

B

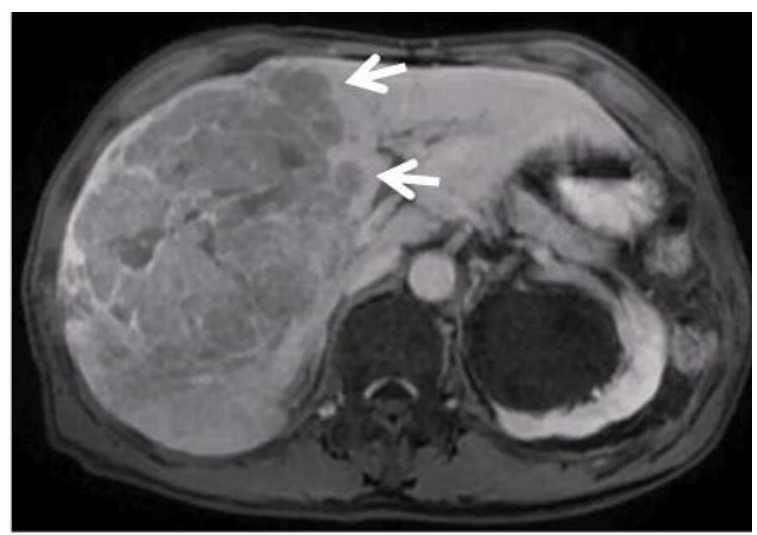

D

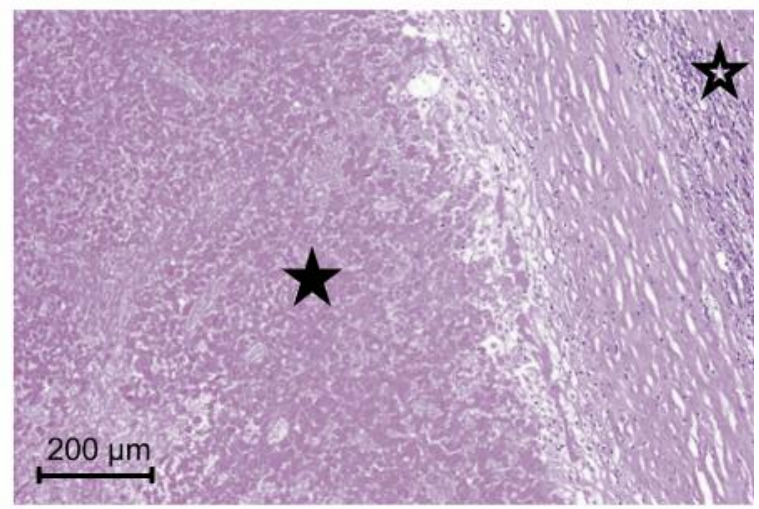

$\mathbf{F}$

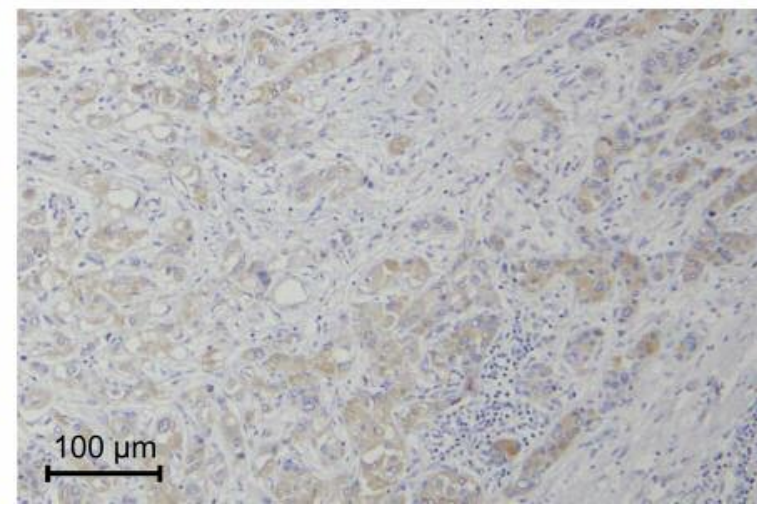

Figure 2. Findings of case 1. Axial contrast-enhanced computed tomography (CT) during the portal phase revealed a lesion with hypervascularity in the right liver lobe with intrahepatic metastatic lesion (circle) (A). A Gadolinium ethoxybenzyl diethylenetriamine pentaacetic acid-enhanced magnetic resonance imaging (Gd-EOB-MRI) showed intrahepatic metastatic lesion in medial segment (arrows) (B). After sorafenib therapy, a CT scan showed significant reduction in the lesion size $(C)$. A curative right hepatic lobectomy was performed and the tumor showed significant pathological response with necrotic change. Microscopically, there was massive necrosis and no viable cells in the tumor ( $\star$ ). Non-tumor tissue (污) (magnification $\times 100$ ) (D). Tissue from the stellate lesion with viable cells showed moderately differentiated hepatocellular carcinoma (HCC) (magnification $\times 200)(E)$ and it was positive for FGF4 (Anti-FGF4 antibody: HPA011209, Sigma-Aldrich, St. Louis, MO, USA) (magnification ×200) (F).

between the baseline and the 3 months after administration $(\triangle \mathrm{AFP}(\%))$ were significantly prognostic of 1 -year OS in only univariate analyses. Finally, macroscopic vascular invasion and response rate were independent prognostic factors of survival in multivariate analyses.
Curtit et al. reported the first case of a patient who achieved CR with sorafenib therapy before surgical resection (3). To obtain better outcomes and achieve a cure, complete surgical resection has been essential in patients with HCC. Reported cases of patients with successful conversion to surgical resection 

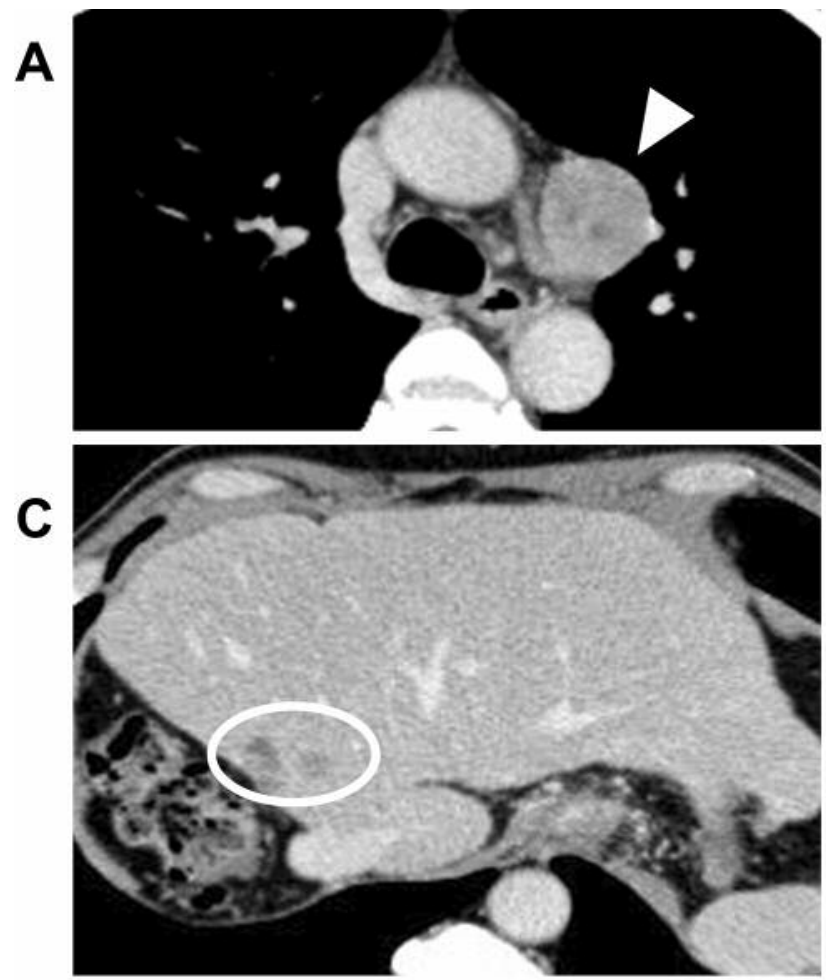

$\mathbf{E}$

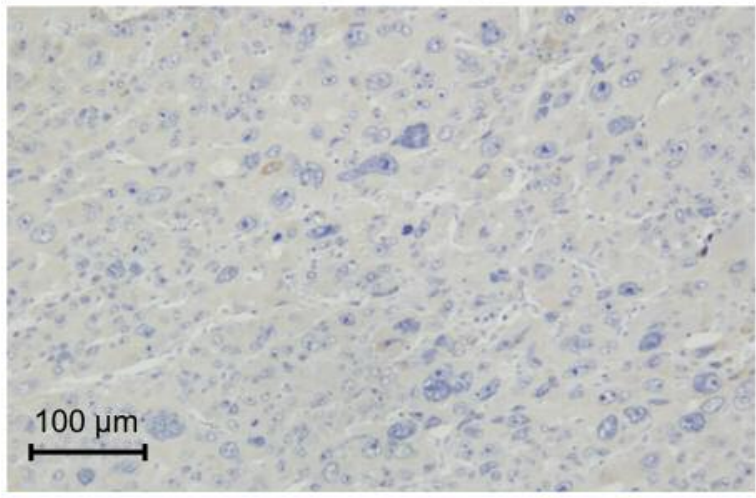

G

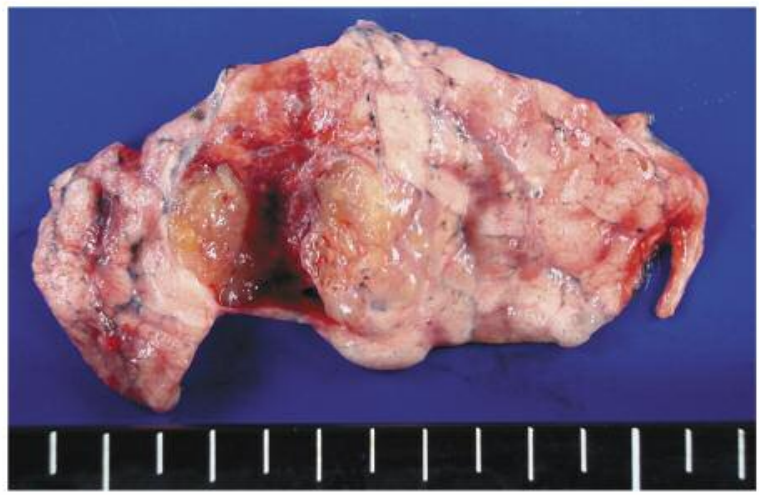

B

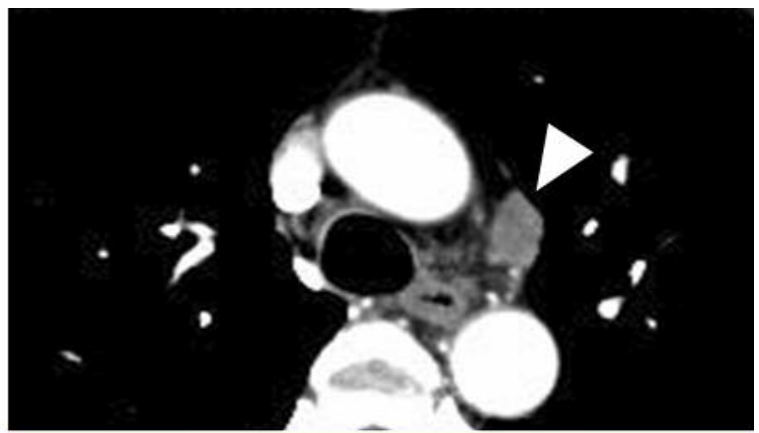

D

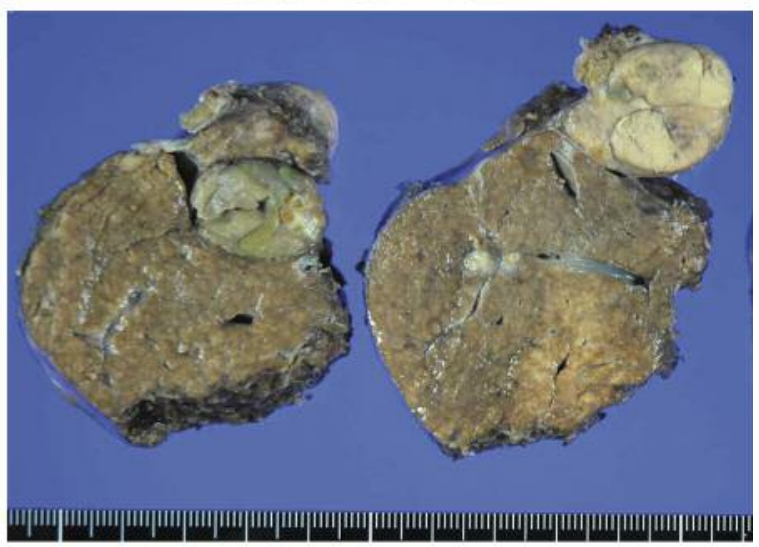

$\mathbf{F}$

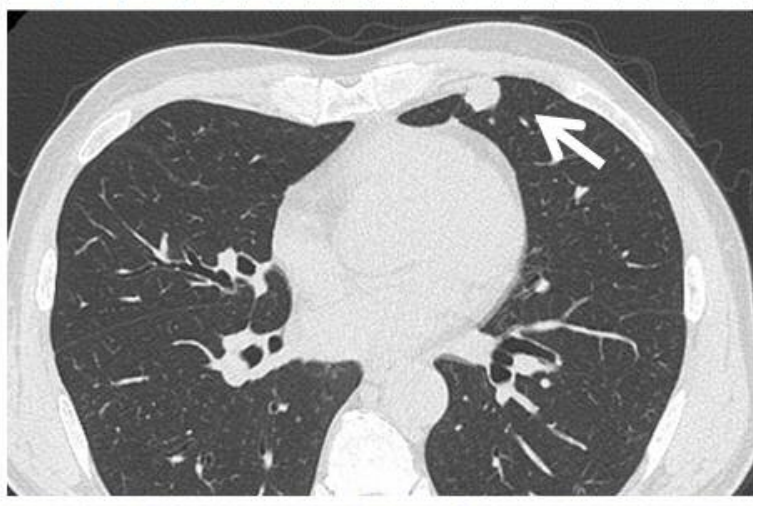

H

$100 \mu \mathrm{m}$

Figure 3. Findings of case 2. A hilar lymph node (LN) metastasis (arrow head) (A) and multiple lung metastasis (not shown) occurred 18 months after hepatectomy for HCC. Sorafenib was introduced and a CT scan showed a size reduction in LN metastasis (arrow) 3 months after starting sorafenib therapy (B). A recurrent tumor in the medial segment (circle) appeared 25 months after starting sorafenib therapy (C). Medial segmentectomy was performed (D) and it showed moderately to poorly differentiated HCC that was negative for FGF4 (magnification $\times 200)(E)$. A CT showed a residual lung tumor (arrow) $(F)$. Partial lung resection was performed $(G)$ and the resected tumor showed metastatic HCC that was negative for FGF4 (magnification $\times 200)(H)$. 
Table III. Reported cases of conversion hepatectomy after sorafenib therapy.

\begin{tabular}{|c|c|c|c|c|c|c|c|c|c|}
\hline \# & $\begin{array}{l}\text { Diameter } \\
(\mathrm{cm})\end{array}$ & $\begin{array}{l}\text { Vascular } \\
\text { thrombus }\end{array}$ & $\begin{array}{l}\mathrm{LN} \\
\text { meta. }\end{array}$ & $\begin{array}{l}\text { Operative } \\
\text { procedure }\end{array}$ & $\begin{array}{l}\text { Postoperative } \\
\text { complication }\end{array}$ & $\begin{array}{l}\text { Pathological } \\
\text { response }\end{array}$ & $\begin{array}{c}\text { Sorafenib } \\
\text { therapy }\end{array}$ & $\begin{array}{l}\text { Outcome after } \\
\text { hepatectomy }\end{array}$ & Ref. \\
\hline 1 & 15 & RHV & & Unknown & Non & $\mathrm{CR}$ & $\begin{array}{c}400 \rightarrow 200 \\
\mathrm{mg} / \text { day, } 6 \mathrm{~m}\end{array}$ & $\begin{array}{c}\text { Alive, } 6 \mathrm{~m} \text {, } \\
\text { no-recurrence }\end{array}$ & 3 \\
\hline 2 & 10 & PV & Mediastinum & Left & Pneumonia & $\mathrm{CR}$ & $\begin{array}{c}800 \mathrm{mg} / \text { day } \\
6 \mathrm{~m}\end{array}$ & $\begin{array}{l}\text { Alive, } 12 \mathrm{~m} \text {, } \\
\text { no-recurrence }\end{array}$ & 4 \\
\hline 3 & 8 & PV & & Lleft & Pleural effusion & $\mathrm{CR}$ & $\begin{array}{c}800 \rightarrow 400 \\
\mathrm{mg} / \text { day, } 12 \mathrm{~m}\end{array}$ & $\begin{array}{l}\text { Alive, } 18 \mathrm{~m} \text {, } \\
\text { no-recurrence }\end{array}$ & 4 \\
\hline 4 & 4.5 & & $\begin{array}{c}\text { Celiac axis, } \\
\text { hepatic hilum }\end{array}$ & Segmentectomy & Non & PR & $\begin{array}{c}800 \mathrm{mg} / \text { day+ } \\
\text { GEMOX, } 4 \text { cycle }\end{array}$ & Unknown & 9 \\
\hline 5 & 12 & PV & & $\begin{array}{l}\text { Extended } \\
\text { right }\end{array}$ & Non & PR & $800 \mathrm{mg} / \mathrm{day}, 9 \mathrm{~m}$ & $\begin{array}{l}\text { Alive, } 12 \mathrm{~m} \text {, } \\
\text { recurrence } \rightarrow \\
\text { re-hepatectomy }\end{array}$ & 8 \\
\hline 6 & 10 & RHV & & Right & Non & PR & $800 \mathrm{mg} /$ day, $9 \mathrm{~m}$ & $\begin{array}{c}\text { Alive, } 6 \mathrm{~m} \text {, } \\
\text { no-recurrence }\end{array}$ & 8 \\
\hline 7 & 10 & PV, IVC & & Partial & Non & PR & $800 \mathrm{mg} / \mathrm{day}, 7 \mathrm{~m}$ & $\begin{array}{l}\text { Alive, } 4 \mathrm{~m}, \\
\text { recurrence } \\
\rightarrow \text { HAIC, RFA }\end{array}$ & 10 \\
\hline 8 & 10 & & & Right & Non & $P R$ & $\begin{array}{c}800 \rightarrow 400 \\
\mathrm{mg} / \text { day, } 3 \mathrm{~m}\end{array}$ & $\begin{array}{c}\text { Alive, } 54 \mathrm{~m}, \\
\text { no-recurrence }\end{array}$ & $*$ \\
\hline
\end{tabular}

RHV: Right hepatic vein; PV: portal vein; IVC: inferior vena cava; CR: complete response; PR: partial response; GEMOX: gemcitabine + oxaliplatin; HAIC: hepatic arterial infusion chemotherapy; RFA: radiofrequency ablation.

*Our patient: Case 1

are rare $(3,4,8-10)$ (Table III). We reviewed seven cases, and all of these cases showed long-term recurrence-free survival.

One of the main concerns with sorafenib therapy before surgical resection is the safety of performing a hepatectomy because sorafenib, a molecular-targeted drug, can increase bleeding and thrombosis, and impair liver regeneration (11). Barbier et al. reported the safety of liver resection for HCC after sorafenib therapy using a case-matched multicenter study (12). In this report, the volume of the blood loss, time of surgery, and incidence of postoperative complications in the sorafenib group was similar to the control group.

Identifying positive responders to sorafenib is a critical issue because of the low response rate to sorafenib therapy. Thus, it is important to define new biomarkers of responsiveness to aid in patient selection (13). If we can identify responders and non-responders to sorafenib, we can avoid unnecessary sorafenib therapy administered to nonresponders. Non-responders need to undergo other therapeutic options, such as radiation or transarterial chemoembolization, which has a higher response rate compared with sorafenib.

For FGF4, it has been reported that a comparative genomic hybridization analysis using one frozen HCC sample from a sorafenib responder demonstrated that the $11 \mathrm{q} 13$ region, a rare amplicon in HCC including the loci for FGF3 and FGF4, was highly amplified. Arao et al. validated FGF3/4 amplification using a real-time polymerase chain reactionbased copy number assay with responder or non-responder tumor tissue. Moreover, a growth inhibitory assay using a FGF3/4-amplified cancer cell line showed hypersensitivity to sorafenib, and it was effective against exogenously expressed FGF4 tumors (5). Therefore, FGF4 may be a novel candidate biomarker for sorafenib therapy. In both of our 2 patients, primary $\mathrm{HCC}$ was positive for FGF4, but sorafenib-resistant lesions including intrahepatic recurrence and HCC lung metastasis were negative for FGF4. In conclusion, this study showed that macroscopic vascular invasion and response rate were independent prognostic factors of survival in patients with advanced HCC treated with sorafenib. A significant pathological response was observed in patients described in the current cases and sorafenib therapy before surgical resection could be a useful therapeutic option for patients with advanced HCC, especially if they are FGF4-positive.

\section{Conflicts of Interest}

The Authors declare that they have no conflicts of interest.

\section{References}

1 Llovet JM, Ricci S, Mazzaferro V, Hilgard P, Gane E, Blanc JF, de Oliveira AC, Santoro A, Raoul JL, Forner A, Schwartz M, Porta C, Zeuzem S, Bolondi L, Greten TF, Galle PR, Seitz JF, Borbath I, Häussinger D, Giannaris T, Shan M, Moscovici M, Voliotis D and Bruix J: Sorafenib in advanced hepatocellular carcinoma. New Eng J Med 359(4): 378-390, 2008. 
2 Cheng AL, Kang YK, Chen Z, Tsao CJ, Qin S, Kim JS, Luo R, Feng J, Ye S, Yang TS, Xu J, Sun Y, Liang H, Liu J, Wang J, Tak WY, Pan H, Burock K, Zou J, Voliotis D and Guan Z: Efficacy and safety of sorafenib in patients in the Asia-Pacific region with advanced hepatocellular carcinoma: a phase III randomised, double-blind, placebo-controlled trial. Lancet Oncol 10(1): 25-34, 2009

3 Curtit E, Thiery-Vuillemin A, Nguyen T, Heyd B, Pivot X, Di Martino $\mathrm{V}$ and Borg C: Complete histologic response induced by sorafenib in advanced hepatocellular carcinoma: a case report. J Clin Oncol 29(12): e330-332, 2011.

4 Irtan S, Chopin-Laly X, Ronot M, Faivre S, Paradis V and Belghiti J: Complete regression of locally advanced hepatocellular carcinoma induced by sorafenib allowing curative resection. Liver Int 31(5): 740-743, 2011.

5 Arao $T$, Ueshima $K$, Matsumoto $K$, Nagai $T$, Kimura $H$, Hagiwara S, Sakurai T, Haji S, Kanazawa A, Hidaka H, Iso Y, Kubota K, Shimada M, Utsunomiya T, Hirooka M, Hiasa Y, Toyoki Y, Hakamada K, Yasui K, Kumada T, Toyoda H, Sato S, Hisai H, Kuzuya T, Tsuchiya K, Izumi N, Arii S, Nishio K and Kudo M: FGF3/FGF4 amplification and multiple lung metastases in responders to sorafenib in hepatocellular carcinoma. Hepatology 57(4): 1407-1415, 2013.

6 Liu L, Zhao Y, Jia J, Chen H, Bai W, Yang M, Yin Z, He C, Zhang L, Guo W, Niu J, Yuan J, Cai H, Xia J, Fan D and Han G: The prognostic value of alpha-fetoprotein response for advanced-stage hepatocellular carcinoma treated with sorafenib combined with transarterial chemoembolization. Scientific reports 2(6): 19851, 2016.

7 Lee S, Kim BK, Kim SU, Park JY, Kim do Y, Ahn SH and Han $\mathrm{KH}$ : Early $\alpha$-fetoprotein response predicts survival in patients with advanced hepatocellular carcinoma treated with sorafenib. J Hepatocell Carcinoma 2: 39, 2015.
8 Barbier L, Muscari F, Le Guellec S, Pariente A, Otal P and Suc B: Liver resection after downstaging hepatocellular carcinoma with sorafenib. Int J Hepatol 2011: 791013, 2011.

9 Williet N, Dubreuil O, Boussaha T, Trouilloud I, Landi B, Housset M, Botti M, Rougier P, Belghiti J and Taieb J: Neoadjuvant sorafenib combined with gemcitabine plus oxaliplatin in advanced hepatocellular carcinoma. World $\mathrm{J}$ Gastroenterol 17(17): 2255-2258, 2011.

10 Deguchi S, Tsukamoto T, Kanazawa A, Shimizu S, Yamamoto S, Murata A, Nakajima T, Sakae M, Tachimori A, Tamamori Y, Yamamoto A, Inoue T, Yamashita Y and Nishiguchi Y: A Case of Multiple HCC with Vp2 and Vv3 Invasion Controlled by Multidisciplinary Treatment Including Surgery. Cancer Chemother 42(12): 1845-1847, 2015.

11 Kudo M: Current status of molecularly targeted therapy for hepatocellular carcinoma: clinical practice. Int J Clin Oncol 15(3): 242-255, 2010.

12 Barbier L, Fuks D, Pessaux P, Muscari F, Le Treut YP, Faivre S and Belghiti J: Safety of liver resection for hepatocellular carcinoma after sorafenib therapy: a multicenter case-matched study. Ann Surg Oncol 20(11): 3603-3609, 2013.

13 Harding JJ and Abou-Alfa GK: Predicting responsiveness to sorafenib: can the determination of FGF3/FGF4 amplifications enrich for clinical benefit? Hepatobiliary Surg Nutr 3(4): 168171, 2014.
Received October 21, 2017

Revised November 1, 2017

Accepted November 2, 2017 